\title{
Decreased Intrathoracic Impedance Associated With OptiVol Alert Can Diagnose Increased B-Type Natriuretic Peptide \\ - MOMOTARO (Monitoring and Management of OptiVol Alert to Reduce Heart Failure Hospitalization) Study -
}

Nobuhiro Nishii, MD; Motoki Kubo, MD; Yoji Okamoto, MD; Satoki Fujii, MD; Atsuyuki Watanabe, MD; Yuko Toyama, MD; Tadakatsu Yamada, MD; Masayuki Doi, MD; Hiroshi Morita, MD; Hiroshi Ito, MD on behalf of MOMOTARO Investigators

\begin{abstract}
Background: Ambulatory measurement of intrathoracic impedance (ITI) with an implanted device may detect increases in pulmonary fluid retention early, but the clinical utility of this method is not well established. The goal of this study was to test whether conventional ITI-derived parameters can diagnose fluid retention that may cause early stage heart failure (HF).
\end{abstract}

\begin{abstract}
Methods and Results: HF patients implanted with high-energy devices with OptiVol (Medtronic) monitoring were enrolled in this study. Patients were monitored remotely. At both baseline and OptiVol alert, patients were assessed on standard examinations, including analysis of serum brain natriuretic peptide (BNP). From April 2010 to August 2011, 195 patients from 12 institutes were enrolled. There were 154 primary OptiVol alert events. BNP level at the alerts was not significantly different from that at baseline. Given that ITI was inversely correlated with log BNP, we added a criterion specifying that the OptiVol alert is triggered only when ITI decreases by $\geq 4 \%$ from baseline. This change improved the diagnostic potential of increase in BNP at OptiVol alert (sensitivity, 75\%; specificity, 88\%).
\end{abstract}

Conclusions: BNP increase could not be identified based on OptiVol alert. Decrease in ITI $\geq 4 \%$ compared with baseline, in addition to the alert, however, may be a useful marker for the likelihood of HF (Clinical trial info: UMIN000003351). (Circ J 2015; 79: 1315-1322)

Key Words: Brain natriuretic peptide; Heart failure; Intrathoracic impedance; OptiVol alert; Remote monitoring

$\mathbf{H}$ eart failure (HF) is one of the most common reasons for hospitalization. ${ }^{1}$ Despite therapeutic advances, the majority of these events are re-admissions because of acute deterioration of chronic HF. ${ }^{2}$ It would be an important advance in diagnostic medicine to be able to identify patients at risk for hospitalization for HF. Most HF-related hospitalizations are due to fluid accumulation, and careful surveillance of fluid status and monitoring of symptoms are critical. HF symptoms and an increase in body weight, however, usually occur late in the course of worsening $\mathrm{HF}$ and are unreliable diagnostic indicators even with day-to-day follow-up of patients with HF.,4 Daily monitoring of the thoracic fluid status with intrathoracic impedance (ITI) is a diagnostic feature of implantable cardioverter defibrillators (ICD) or can be carried out in combination with cardiac resynchronization therapy (CRT-D). The monitoring of ITI may provide helpful information for the early detection of HF decompensation, because it is commonly preceded by a gradual increase in pulmonary fluid over several days or weeks. $^{5-9}$

Received January 21, 2015; accepted February 5, 2015; released online March 17, 2015 Time for primary review: 8 days

Department of Cardiovascular Therapeutics (N.N., H.M.), Department of Cardiovascular Medicine (M.K., H.I.), Okayama University Graduate School of Medicine, Dentistry, and Pharmaceutical Sciences, Okayama; Department of Cardiovascular Medicine, Kurashiki Central Hospital, Kurashiki (Y.O., S.F.); Department of Cardiovascular Medicine, Fukuyama City Hospital, Fukuyama (A.W.); Department of Cardiovascular Medicine, Sakakibara Heart Institute of Okayama, Okayama (Y.T.); Department of Cardiovascular Medicine, Ehime Prefectural Central Hospital, Ehime (T.Y.); and Department of Cardiovascular Medicine, Kagawa Prefectural Central Hospital, Takamatsu (M.D.), Japan

Mailing address: Nobuhiro Nishii, MD, Department of Cardiovascular Therapeutics, Okayama University Graduate School of Medicine, Dentistry, and Pharmaceutical Sciences, 2-5-1 Shikata-cho, Kita-ku, Okayama 700-8558, Japan. E-mail: nnishii@md.okayama-u.ac.jp; nnnnishii2001@yahoo.co.jp

ISSN-1346-9843 doi:10.1253/circj.CJ-15-0076

All rights are reserved to the Japanese Circulation Society. For permissions, please e-mail: cj@j-circ.or.jp 


\begin{tabular}{|c|c|}
\hline Characteristics & Mean \pm SD or $n(\%)$ \\
\hline$n$ & 195 \\
\hline Male & $149(76.4)$ \\
\hline Age (years) & $66.3 \pm 11.3$ \\
\hline Height (m) & $1.61 \pm 0.10$ \\
\hline Weight (kg) & $59.8 \pm 12.9$ \\
\hline $\mathrm{SBP}(\mathrm{mmHg})$ & $113.9 \pm 20.3$ \\
\hline $\mathrm{DBP}(\mathrm{mmHg})$ & $68.0 \pm 10.6$ \\
\hline Heart rate (beats/min) & $69.9 \pm 10.6$ \\
\hline \multicolumn{2}{|l|}{ Heart disease type } \\
\hline Ischemic & $55(28.2)$ \\
\hline Non-ischemic & $140(71.8)$ \\
\hline NYHA I/II/III/IV & $\begin{array}{c}66(34.0) / 98(50.3) / \\
31(16.0) / 0(0)\end{array}$ \\
\hline Ejection fraction (\%) & $44.3 \pm 14.3$ \\
\hline Serum BNP (pg/ml) & $254 \pm 275$ \\
\hline Log BNP & $2.2 \pm 0.5$ \\
\hline Serum BUN (mg/dl) & $22.3 \pm 10.9$ \\
\hline Serum creatinine (mg/dl) & $1.17 \pm 0.75$ \\
\hline Cardiothoracic ratio on chest X-ray (\%) & $54.7 \pm 6.8$ \\
\hline \multicolumn{2}{|l|}{ Medications } \\
\hline ACEI or ARB & $146(74.8)$ \\
\hline$\beta$-blocker & $171(87.7)$ \\
\hline Diuretics & $147(75.4)$ \\
\hline Anti-arrhythmic drugs & $111(56.9)$ \\
\hline
\end{tabular}

$A C E I$, angiotensin-converting enzyme inhibitor; $A R B$, angiotensin receptor blocker; BNP, brain natriuretic peptide; BUN, blood urea nitrogen; DBP, diastolic blood pressure; NYHA, New York Heart Association; SBP, systolic blood pressure.

\section{Editorial p 1209}

OptiVol (Medtronic, Minneapolis, MN, USA) alert, which is a fluid status algorithm calculated from ITI trends, was designed to diagnose impending fluid accumulation before HF symptoms. ${ }^{5}$ Whether it is possible to diagnose worsening HF with current technology is a controversial issue..$^{10-19}$ Therefore, we conducted a multicenter trial to test whether the OptiVol alert can diagnose early stages of $\mathrm{HF}$, which we defined as an increase in brain natriuretic peptide (BNP). We also assessed retrospectively whether additional analysis of ITI trends may improve the diagnostic accuracy of this method.

\section{Methods}

\section{Patients}

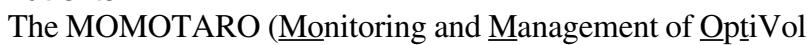
Alert to Reduce Heart Failure Hospitalization) Study was a prospective observational study that was carried out at 12 medical centers. Patients with either ischemic or non-ischemic heart disease were eligible for the study. Patients with either preserved or reduced left ventricular ejection fraction $(\mathrm{EF})$ were included in this study. The ICD patients with preserved EF underwent implantation for secondary prevention and the patients with hypertrophic cardiomyopathy underwent implantation for primary prevention. The CRT-D patients with EF $>35 \%$ have been improved in EF after CRT-D implantation. All patients had ICD or CRT-D with OptiVol 1.0 feature (models 7297, 7303, 7277,7289 , or C154DWK; Medtronic). Devices were implanted in the pectoral region, preferably on the left side. Patients who were having a device implanted for the first time as well as those with existing devices were included in this study. We excluded patients who were $<18$ years old, scheduled for or had undergone cardiac surgery in the last 90 days, and those who were listed for heart transplantation. Further exclusion criteria were moderate-severe chronic obstructive lung disease (forced expiratory volume $<1.0 \mathrm{~L} / \mathrm{s}$ ), life expectancy $<1$ year, hemodialysis, primary pulmonary hypertension, and pregnancy or breastfeeding. All patients gave their written informed consent, and the study protocol was approved by the Institutional Review Board and/or Medical Ethics Committee of each center.

\section{Study Design and Event Definitions}

Patients were enrolled in this study after at least a 1-month waiting period to allow postoperative clinical stabilization, resolution of pocket edema, and automatic calibration of the impedance reference. Baseline examination included laboratory tests (including serum BNP), physical examination, chest X-ray, 12-lead electrocardiogram (ECG) and echocardiography. If patients were without HF sign based on physical examination, chest X-ray and echocardiography, and ITI trend was stable without large fluctuation, patients were enrolled in this study. Medical therapy was optimized during this time period.

Patients were followed up every 3-6 months in an outpatient clinic until 24 months after enrollment; the study ended in August 2013. The devices were tested at enrollment and at routine outpatient visits. In addition, all device-based diagnostic information, including the alert for increased pulmonary fluid retention, was followed by a wireless remote monitoring system (CareLink network). Fluid status monitoring with OptiVol was based on calculations of the average daily ITI measured between the right ventricular defibrillation electrode and the device case. Temporal changes in ITI were compared with the reference impedance, which was derived from a moving average algorithm, to assess fluid status. When daily impedance consistently fell below the reference, the differences were added to generate the OptiVol fluid index. When this index exceeded a threshold $(60 \Omega)$, the OptiVol alert was sent to the analysis center (Okayama University). Audible patient alert was turned off in this study. Additional device data were collected for all device alerts, at all unscheduled visits and all hospitalizations, and at study exit.

Whenever an OptiVol alert was noted on the remote monitoring system, the protocol required patient-physician contact within 3 days. Patients underwent clinical evaluation, laboratory tests, chest X-ray, 12-lead ECG, and echocardiography in the outpatient clinic. If they had decompensated HF, they were treated according to a standardized treatment protocol. ${ }^{20}$

\section{Endpoints}

The primary endpoint was serum BNP at OptiVol alert in comparison with that at baseline. BNP was expressed as a logarithmic function. We defined increased $\log \mathrm{BNP}$ as an increase by 0.4 points compared with that at baseline, because this increase would indicate that BNP had more than doubled. The secondary endpoints included the potential changes in other laboratory and echocardiographic parameters between OptiVol alert and baseline. We retrospectively analyzed what parameters could predict an increasing log BNP.

\section{Statistical Analysis}

Continuous data are expressed as mean $\pm \mathrm{SD}$, and categorical data are expressed as the percentage. BNP data were also log transformed because the distribution of plasma BNP did not 
appear to be normal (ie, the data were skewed). ${ }^{21}$ The change in the measured value between baseline and OptiVol alert or during regular examination for each factor was evaluated using paired t-test. The optimal cut-off was determined using a receiver operating characteristic (ROC) curve ${ }^{22}$ produced by plotting the sensitivity and specificity of the ITI ratio (ratio of ITI at OptiVol alert to that at baseline) vs. $\log$ BNP. $\mathrm{P}<0.05$ was considered statistically significant. All statistical analysis was performed using SPSS (SPSS version 21; IBM, Chicago, IL, USA).

\section{Results}

\section{Patient Characteristics}

From April 2010 to August 2011, 200 patients in 12 institutes were enrolled in this study. Five out of 200 patients were subsequently excluded according to the exclusion criteria. Mean patient age was $66.3 \pm 11.3$ years, and there were 149 male patients (76.4\%). Mean left ventricular EF was $44.3 \pm 14.3 \%$, mean BNP was $254 \pm 275 \mathrm{mg} / \mathrm{dl}$ (range, $4-1,558 \mathrm{pg} / \mathrm{ml}$; mean log BNP, $2.2 \pm 0.5$ ), mean serum blood urea nitrogen was $22.3 \pm 10.9 \mathrm{mg} / \mathrm{dl}$ and mean serum creatinine was $1.17 \pm 0.75 \mathrm{mg} / \mathrm{dl}$. Patient characteristics are listed in Table 1.

\section{Primary Endpoints}

During the follow-up period (mean, 658 \pm 165 days), there were 154 primary OptiVol alert events. There was no significant difference in log BNP between baseline and OptiVol alert ( $2.21 \pm 0.45$ vs. $2.24 \pm 0.46, \mathrm{P}=0.21$; Figure 1$)$ and in $\mathrm{BNP}$ between baseline and OptiVol alert $(258 \pm 260 \mathrm{pg} / \mathrm{ml}$ vs. $280 \pm 293 \mathrm{pg} / \mathrm{ml}, \mathrm{P}=0.18$ ).

\section{False-Positive OptiVol Alerts}

The poor predictive potential of OptiVol alerts resulted from

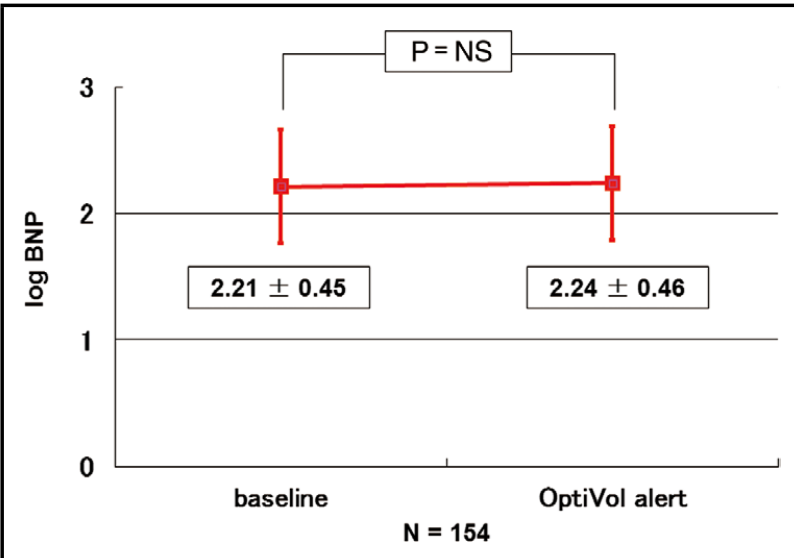

Figure 1. Change in log brain natriuretic peptide (BNP) between OptiVol alert and baseline. In all primary OptiVol alert events, there was no significant (NS) difference in log BNP between OptiVol alert and baseline.

many false-positive events. We found 3 false-positive alert patterns for ITI trends. These false-positive patterns were defined based on ITI patterns from the raw data. The first was "cross to reference" (57 of 154 events), in which the ITI trend crossed the reference line without a decrease in ITI compared with baseline (Figure 2A). The second was "spontaneous recovery" (62 of 154 events), in which the ITI trend was below the reference curve for several days but spontaneously recovered to baseline (Figure 2B). The third was "temporary elevation" (28 of 154 events), in which a temporary increase in ITI was associated with an upward deviation of the reference curve, followed
A

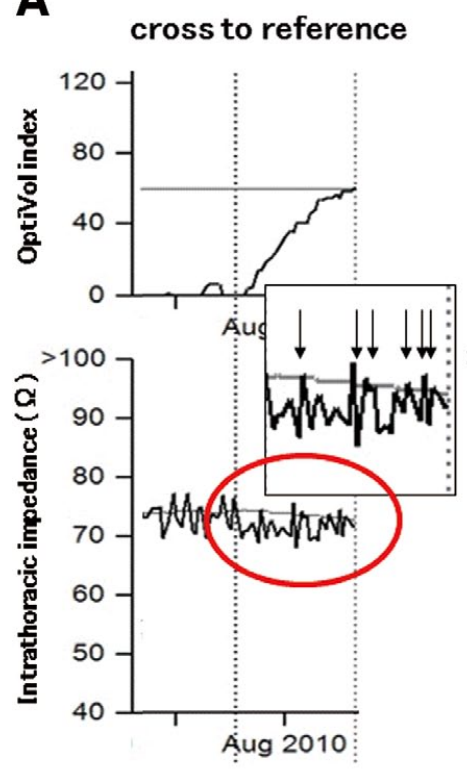

B

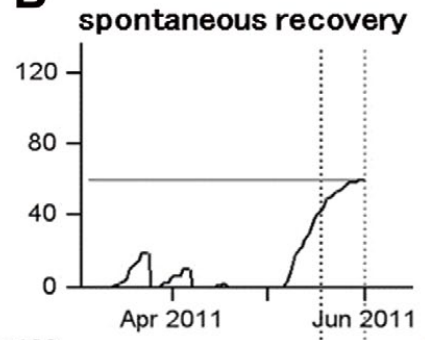

C

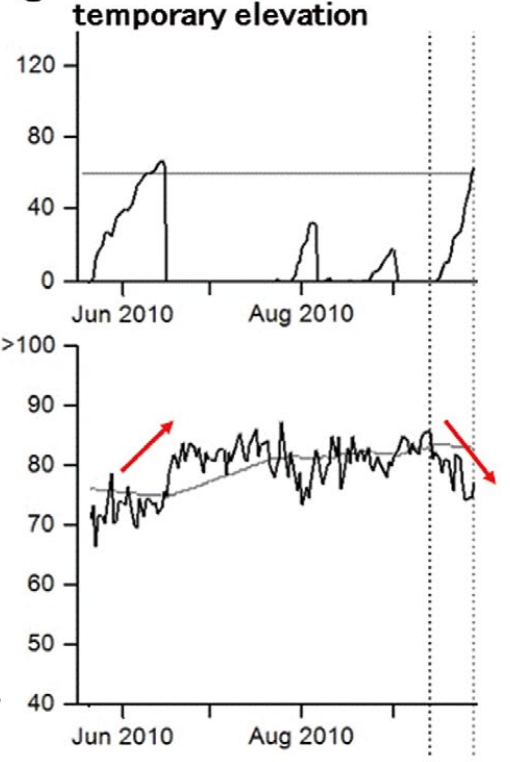

Figure 2. Intrathoracic impedance trends before false-positive OptiVol alert: (A) cross to reference (black arrows, individual cross to reference event); (B) spontaneous recovery; and (C) temporary elevation. 


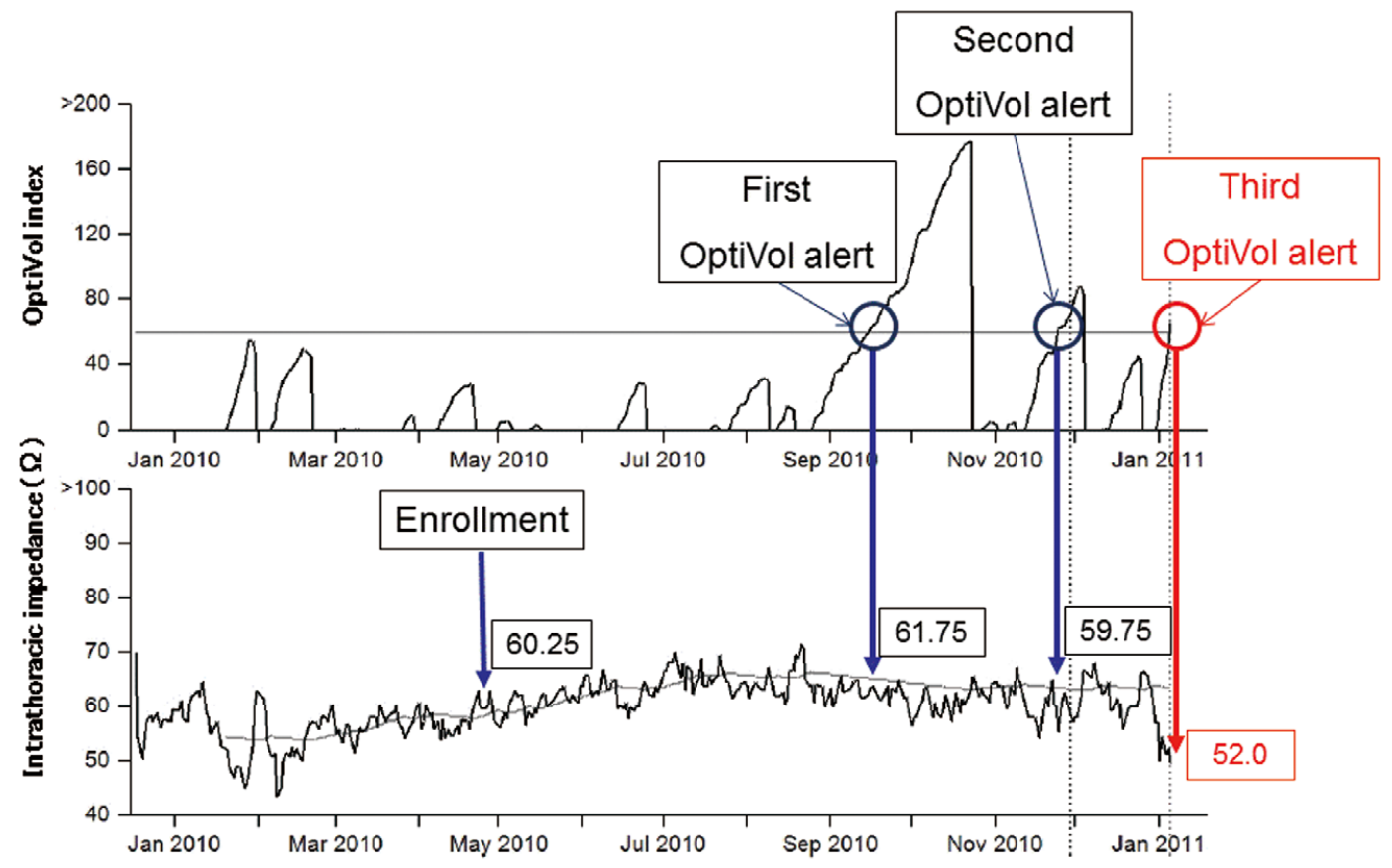

Figure 3. Representative case of false- and true-positive OptiVol alerts. The patient was enrolled on April 2010. The first and second OptiVol alert events were false, because there was no sign of heart failure. The third OptiVol alert, however, was true, because he suffered from early stage heart failure, therefore due to this alert this patient was able to avoid heart failure hospitalization. The difference between false and true OptiVol alert event was the value of intrathoracic impedance (ITI) in this patient: ITI, $60.25 \Omega$ at enrollment; $61.75 \Omega$ at first OptiVol alert; $59.75 \Omega$ at second OptiVol alert; $52.0 \Omega$ at third OptiVol alert.

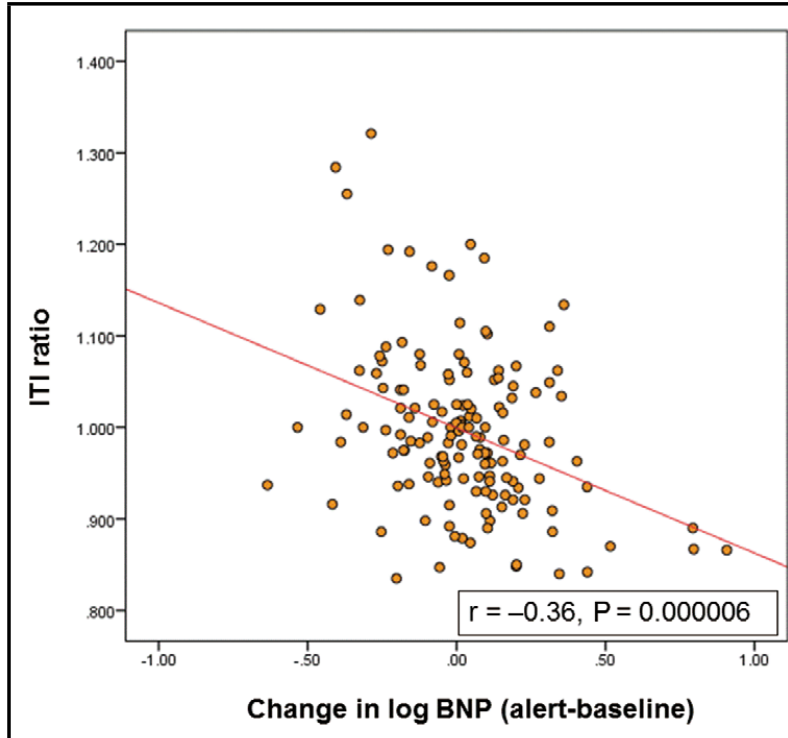

Figure 4. Relationship between change in log brain natriuretic peptide (BNP) between the OptiVol alert and baseline and the intrathoracic impedance (ITI) ratio (ie, ratio of ITI at OptiVol alert to that at baseline). There was a significant relationship between ITI ratio and the change in log BNP $(P=0.000006)$. by a decrease in the ITI trend toward baseline (Figure 2C). All 3 patterns can cause an OptiVol alert based on the algorithm of this monitoring device, whereas the actual ITI value at the time of the alert was similar to the baseline level. Of the 154 OptiVol alert events, $109(71 \%)$ had at least 1 of these 3 characteristics. For these events, there was no difference in log BNP between OptiVol alert and baseline (2.22 \pm 0.46 vs. $2.21 \pm 0.46, \mathrm{P}=0.56)$ or in $\mathrm{BNP}(267 \pm 276 \mathrm{pg} / \mathrm{ml}$ vs. $254 \pm 245 \mathrm{pg} / \mathrm{ml}$, $\mathrm{P}=0.46)$. In these patients, mean $\Delta \log \mathrm{BNP}(\log \mathrm{BNP}$ at OptiVol alert-log BNP at baseline) was $-0.01 \pm 0.22$. In contrast, 45 OptiVol alerts did not have any characteristics of a false positive. In these events, the log BNP at OptiVol alert was significantly higher than that at baseline (baseline vs. OptiVol alert: $2.21 \pm 0.46$ vs. $2.33 \pm 0.49, \mathrm{P}=0.002$ ), as was BNP $(260 \pm 240 \mathrm{pg} / \mathrm{ml}$ vs. $365 \pm 393 \mathrm{pg} / \mathrm{ml}, \mathrm{P}=0.007)$. In these patients, mean $\Delta \log \mathrm{BNP}$ was $0.11 \pm 0.23$. Thus, we referred to these 3 ITI patterns as false-positive patterns, but it was not perfect, and there were some exceptions. Representative case of both false and true OptiVol alert events are shown in Figure 3.

\section{New ITI Parameter to Predict HF Events}

We calculated the ratio of ITI at OptiVol alert to that at baseline. We named this the "ITI ratio" and tested it as a new potential parameter to detect HF. OptiVol alert data were not available for 6 of the 154 primary alert events, because we could not directly access the OptiVol data in these instances. In 148 primary OptiVol alert events, there was a significant relationship between ITI ratio and difference in $\log \mathrm{BNP}(\mathrm{r}=-0.36$, $\mathrm{P}=0.000006$; Figure 4). This suggests that a change in ITI reflects a change in BNP. Therefore, we hypothesized that the magnitude of the decrease of ITI at OptiVol alert might predict 
an increase in BNP.

To test the feasibility of using ITI ratio as a predictor of worsening HF, we collected data from the 148 primary OptiVol alert events and the primary 102 periodic outpatient clinic visits. The area under the ROC curve with respect to ITI ratio for predicting increase in $\log \mathrm{BNP} \geq 0.4$ was significantly larger than that with respect to the OptiVol alert (0.81 vs. $0.64, \mathrm{P}=0.0078$; Figure 5). On ROC analysis, ITI ratio $=0.96$ could predict the events leading to $\mathrm{HF}$ when there is an increase in log BNP $\geq 0.4$, with a sensitivity of $75 \%$ and specificity of $88 \%$.

Forty-nine OptiVol alert events had ITI ratio $\leq 0.96$, and for these alerts log BNP was significantly higher at OptiVol alert than at baseline (baseline vs. OptiVol alert: $2.19 \pm 0.49$ vs. $2.31 \pm 0.47, \mathrm{P}=0.004$; Figure 6A), as was BNP $(249 \pm 260 \mathrm{pg} / \mathrm{ml}$ vs. $326 \pm 342 \mathrm{pg} / \mathrm{ml}, \mathrm{P}=0.03$ ). In 99 OptiVol alert events in which ITI ratio was $>0.96$, there was no increase in log BNP between baseline and OptiVol alert (baseline vs. OptiVol alert: $2.21 \pm 0.44$ vs. $2.18 \pm 0.46, \mathrm{P}=0.20$; Figure $6 \mathrm{~B}$ ) nor in $\mathrm{BNP}$ $(258 \pm 262 \mathrm{pg} / \mathrm{ml}$ vs. $252 \pm 266 \mathrm{pg} / \mathrm{ml}, \mathrm{P}=0.73)$.

\section{Secondary Endpoints}

We also analyzed the 154 primary OptiVol alert events for secondary endpoints including body weight, dimension of inferior vena cava, early-to-late ventricular filling velocities (E/A ratio), and the pressure gradient of tricuspid regurgitation (TRPG). We also measured the number of red blood cells, hemoglobin, total protein, and albumin (Table 2). At OptiVol alert with ITI ratio $\leq 0.96$, we found that the dimension of the inferior vena cava, E/A ratio, and TRPG had significantly increased, whereas red blood cells, hemoglobin, total protein, and albumin were all significantly lower than at baseline. At OptiVol alert with ITI ratio $>0.96$, however, there were no significant differences in any of these parameters between OptiVol alert and baseline. Therefore, the parameters associated with fluid retention were also changed only at OptiVol alert with ITI ratio $\leq 0.96$. Increase in body weight is another sign of developing HF, but there was no statistically significant difference in body weight between baseline and alert, even for ITI ratio $\leq 0.96$ (Table 2).

During follow-up, there were 11 deaths and 23 HF hospitalizations. At the time of HF hospitalization, ITI was decreased approximately $10 \%$ compared with that at baseline $(63.4 \pm 8.8 \Omega$

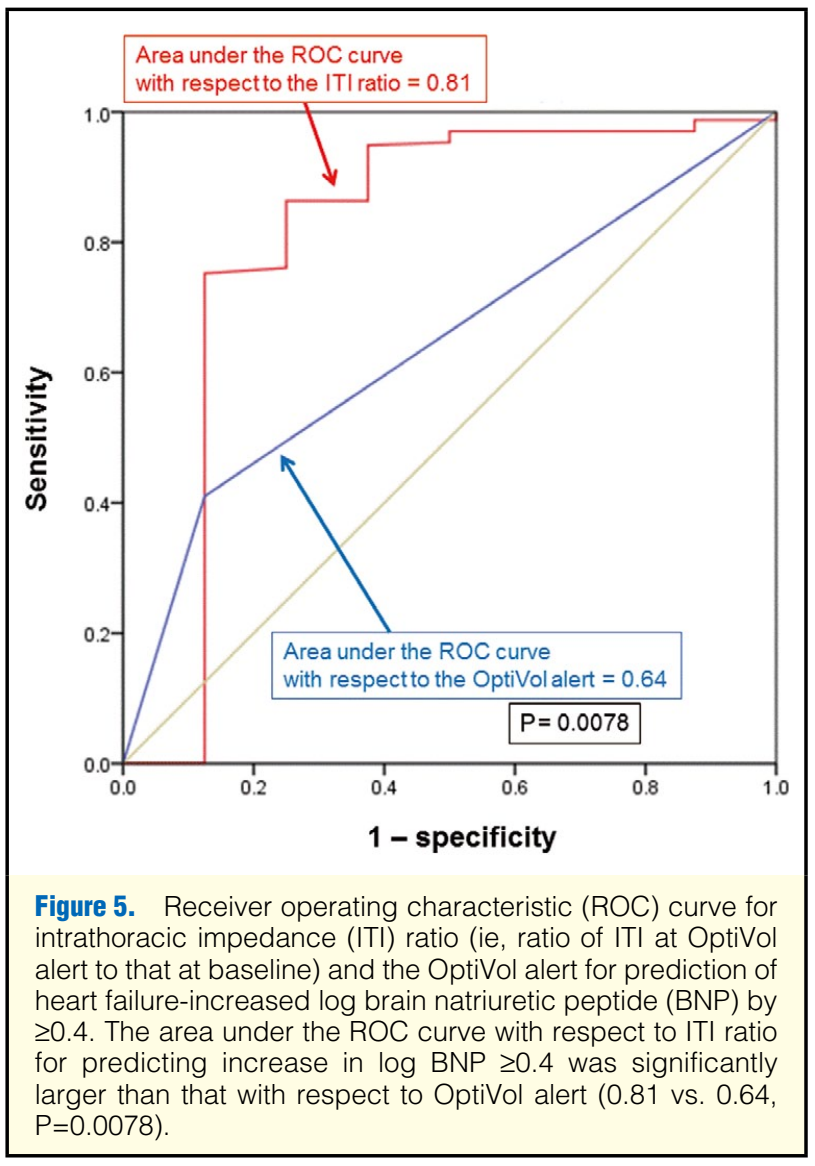

vs. $70.0 \pm 7.4 \Omega, \mathrm{P}=0.001$ ). For patients who underwent $\mathrm{HF}$ hospitalization, ITI ratio was $\leq 0.96$ on $12.8 \pm 12.7$ days before hospitalization. Thus, if we focused on ITI ratio as well as on OptiVol alert, we could detect the state of fluid retention before HF hospitalization.

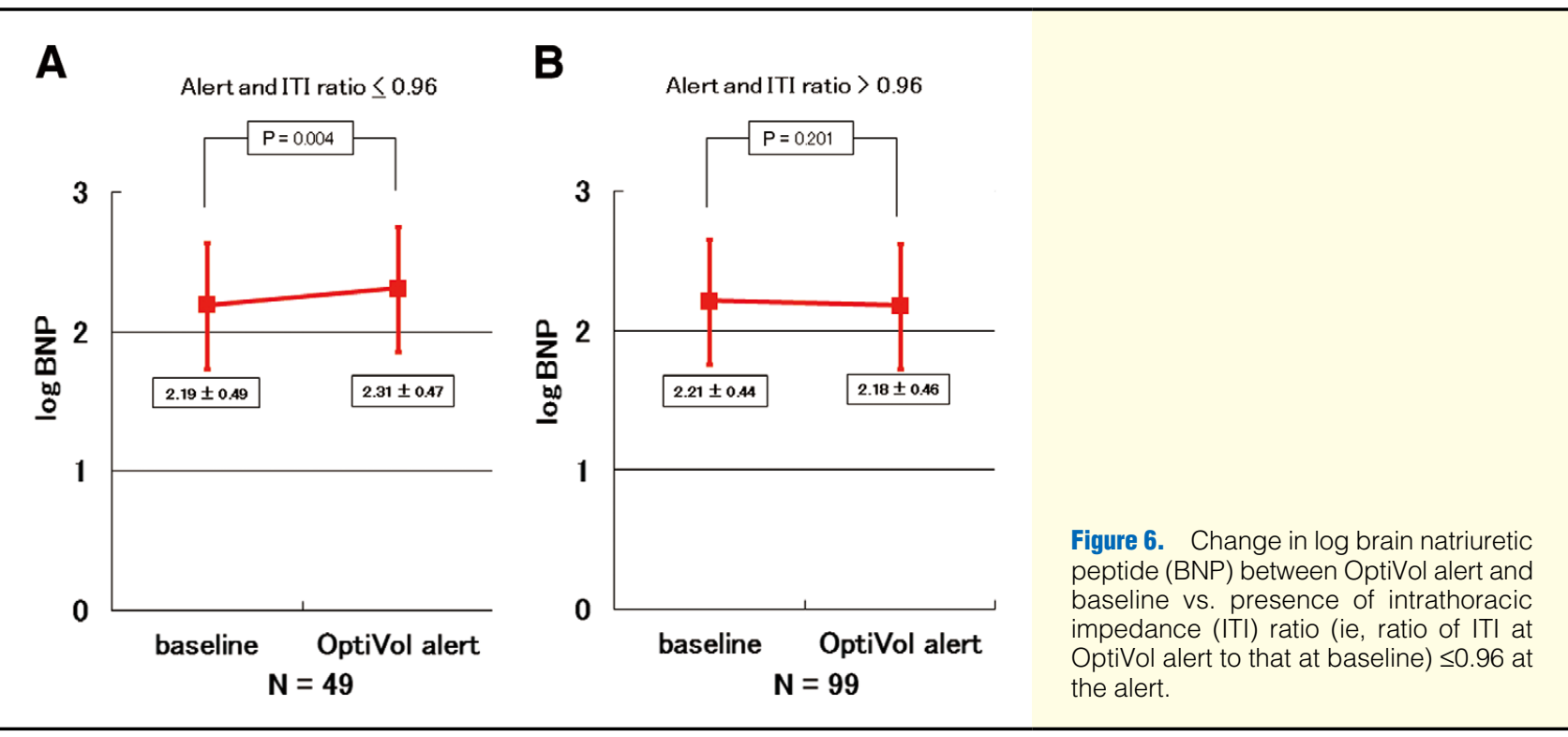


Table 2. Secondary Endpoints vs. Presence of ITI Ratio $\leq 0.96$

\begin{tabular}{|c|c|c|c|c|c|c|c|c|c|}
\hline \multirow{2}{*}{ Parameter } & \multicolumn{2}{|c|}{ All $(n=154)$} & \multirow{2}{*}{ P-value } & \multicolumn{2}{|c|}{ ITI ratio $\leq 0.96(n=49)$} & \multirow{2}{*}{ P-value } & \multicolumn{2}{|c|}{ ITI ratio >0.96 $(n=99)$} & \multirow{2}{*}{ P-value } \\
\hline & Baseline & OptiVol alert & & Baseline & OptiVol alert & & Baseline & OptiVol alert & \\
\hline IVC (E) (mm) & $14.3 \pm 5.4$ & $15.3 \pm 5.8$ & 0.009 & $13.7 \pm 4.8$ & $15.7 \pm 6.9$ & 0.002 & $14.4 \pm 5.5$ & $15.0 \pm 5.2$ & 0.296 \\
\hline IVC (I) (mm) & $5.3 \pm 5.3$ & $6.4 \pm 5.9$ & 0.010 & $4.5 \pm 4.6$ & $7.3 \pm 6.6$ & 0.001 & $5.6 \pm 5.5$ & $5.7 \pm 5.3$ & 0.847 \\
\hline E wave $(\mathrm{cm} / \mathrm{s})$ & $68.1 \pm 29.9$ & $71.7 \pm 33.0$ & 0.005 & $63.7 \pm 26.7$ & $73.0 \pm 32.3$ & 0.00007 & $70.3 \pm 31.9$ & $71.2 \pm 33.9$ & 0.535 \\
\hline$E / A$ & $1.02 \pm 0.82$ & $1.12 \pm 0.88$ & 0.028 & $0.83 \pm 0.52$ & $1.03 \pm 0.58$ & 0.002 & $1.06 \pm 0.86$ & $1.11 \pm 0.92$ & 0.427 \\
\hline TRPG (mmHg) & $25.3 \pm 8.5$ & $27.2 \pm 9.1$ & 0.004 & $24.2 \pm 7.5$ & $27.9 \pm 9.2$ & 0.002 & $25.6 \pm 8.5$ & $26.8 \pm 8.9$ & 0.129 \\
\hline $\operatorname{RBC}\left(10^{6} / \mu \mathrm{l}\right)$ & $4.16 \pm 0.60$ & $4.07 \pm 0.60$ & 0.004 & $4.02 \pm 0.60$ & $3.78 \pm 0.59$ & 0.000001 & $4.21 \pm 0.54$ & $4.20 \pm 0.52$ & 0.845 \\
\hline $\mathrm{Hb}(\mathrm{g} / \mathrm{dl})$ & $13.1 \pm 1.8$ & $12.9 \pm 1.9$ & 0.033 & $12.6 \pm 1.7$ & $11.9 \pm 1.8$ & 0.000003 & $13.2 \pm 1.7$ & $13.3 \pm 1.7$ & 0.763 \\
\hline TP (g/dl) & $7.1 \pm 0.5$ & $7.0 \pm 0.5$ & 0.016 & $7.1 \pm 0.5$ & $6.9 \pm 0.6$ & 0.007 & $7.1 \pm 0.6$ & $7.1 \pm 0.5$ & 0.361 \\
\hline Alb (g/dl) & $4.2 \pm 0.4$ & $4.1 \pm 0.4$ & 0.0497 & $4.2 \pm 0.3$ & $4.0 \pm 0.4$ & 0.001 & $4.2 \pm 0.4$ & $4.2 \pm 0.4$ & 0.794 \\
\hline Body weight (kg) & $60.2 \pm 13.5$ & $60.8 \pm 13.2$ & 0.062 & $58.1 \pm 12.5$ & $58.7 \pm 12.1$ & 0.234 & $61.2 \pm 13.6$ & $61.7 \pm 13.4$ & 0.220 \\
\hline
\end{tabular}

Data given as mean \pm SD. Raw data for ITI were not available for 8 OptiVol alert events. Alb, albumin; Hb, hemoglobin; ITI ratio, ratio of intrathoracic impedance at OptiVol alert to that at baseline; IVC (E), dimension of the inferior vena cava at expiration; IVC (I), dimension of the inferior vena cava at inspiration; RBC, red blood cells; TP, total protein; TRPG, pressure gradient of tricuspid regurgitation.

\section{Discussion}

Only the OptiVol alerts with ITI ratio $\leq 0.96$ were associated with an increase in log BNP and significant changes in E/A ratio, TRPG, dimension of the inferior vena cava, and red blood cells, hemoglobin, total protein, and albumin, which are indicative of fluid retention. These parameters did not change in the OptiVol alerts with ITI ratio $>0.96$. Therefore, at the time of OptiVol alert, there should be additional analysis of ITI trend to diagnose HF events accurately. Only when ITI ratio is $\leq 0.96$ can we predict fluid retention that may cause early stage HF (with modest sensitivity and high specificity), even when it is not associated with noticeable physical symptoms.

\section{Differentiation of False-Positive OptiVol Alert Events}

There have been several reports that OptiVol alerts do not predict impending HF hospitalization. ${ }^{13-15}$ These reports were due to a high percentage of false-positive alerts. In this study, we also found that two-thirds of OptiVol alerts are false positives, with log BNP not changing between baseline and alert. We focused on analyzing ITI itself. Previous studies demonstrated that ITI is inversely correlated with (1) left ventricular end diastolic pressure in a canine HF model; ${ }^{23}$ (2) pulmonary artery wedge pressure; ${ }^{5}$ and (3) right ventricular pressure. ${ }^{24}$ The present study suggests that a decrease $\geq 4 \%$ in ITI ratio at alert can indicate an increase in $\log \mathrm{BNP} \geq 0.4$ with reasonable accuracy. At this level of BNP increase, most of the patients did not require hospitalization (data not shown). If we focus on decreased ITI at OptiVol alert, we may be able to differentiate between false-positive and accurate OptiVol alert events.

\section{ITI Trends: New Therapeutic Target to Reduce HF Hospitalization}

A decrease in ITI is 1 way to diagnose lung congestion..$^{5,24}$ This study showed that ITI ratio $\leq 0.96$ at the time of OptiVol alert can predict increase in log brain natriuretic peptide (BNP) $\geq 0.4$. Lüthje et al reported that natriuretic peptide-proBNP is increased at the time of OptiVol alerts as compared with times without HF symptoms and that a change in ITI is negatively correlated with a change in N-terminal-proBNP. ${ }^{25}$ Similarly, in this study, ITI ratio $\leq 0.96$ at the time of OptiVol alert was associated with an increase in TRPG, dimension of the inferior vena cava, and E/A ratio and was also correlated with a reduction in the number of red blood cells, hemoglobin, total protein, and albumin, all of which relate to fluid retention. ICD and
CRT-D, which have remote monitoring systems, are commonly implanted in patients with an especially high risk of HF. Therefore, if we could administer drugs at the time of OptiVol alert with decreased ITI ratio, we might reduce HF hospitalizations. We have a number of indexes to predict increased BNP, such as OptiVol alert, ITI ratio, and ITI ratio independent of the OptiVol index. Recent ICD and CRT-D have the alert triggered by the OptiVol alert, but not by ITI ratio. It was not known whether ITI ratio independent of OptiVol index was useful to predict increased BNP. In this study, ITI ratio was more useful to predict increased BNP than the OptiVol alert.

\section{Self-Adjusting Running Average Algorithm}

Three types of false positive were produced, possibly because of the self-adjusting running average algorithm used by this device. The cross to reference pattern occurred when the ITI trend crossed the reference line several times without a decrease in ITI, but the area under the reference line reached the threshold for an alert. In the spontaneous recovery pattern, the ITI trend was below the reference curve for several days, and the area under the reference curve reached the threshold, but the ITI spontaneously recovered to the baseline level. In the temporary elevation pattern, ITI increased and was associated with an upward deviation of the reference curve, followed by a decrease in the ITI trend toward baseline. This usually occurred during transient dehydration. An important point for each of these false positives is that the final ITI was the same as that at baseline.

\section{Selection of Threshold for OptiVol Alerts}

In this study, we used a nominal threshold for OptiVol alerts $(60 \Omega)$, given that 2 prospective double-blind clinical trials have shown a reasonable sensitivity of this threshold for predicting HF hospitalizations. ${ }^{5,16}$ We observed, however, that two-thirds of alert events were not associated with decreased ITI. Other studies reported that a higher threshold can increase the specificity and decrease the number of false-positive signals..$^{25,26} \mathrm{In}$ the current study, however, OptiVol alert was set to occur at a nominal threshold of $60 \Omega$, and these alerts might have influenced the incidence of subsequent HF events. We encountered several decompensated HF events before the fluid index reached the nominal threshold in this study. A subsequent prospective study is required to test whether a higher threshold can improve the accuracy for predicting HF events. 


\section{Remote Monitoring}

We followed all patients by remote monitoring. There have been many studies on the advantages of remote monitoring, such as reduction of workload associated with device followup, ${ }^{27}$ similar safety to outpatient device follow-up, ${ }^{28,29}$ early detection of arrhythmic or adverse events, ${ }^{28}$ and improvement of prognosis. ${ }^{30}$ OptiVol alert with decreased ITI is also useful for remote monitoring. We can receive notification of OptiVol alert with decreased ITI, even though patients are at home and do not have any symptoms. We can also receive notification for various parameters associated with $\mathrm{HF}$, such as heart rate, heart rate variability, arrhythmic events, and activity by remote monitoring. If we could combine various parameters, we may predict early stage HF more precisely.

\section{Study Limitations}

There are several limitations in this study. First, this study was unable to validate multimodal $\mathrm{HF}$ detection algorithms of devices because of the relatively small sample size. For example, the Cardiac Compass (Medtronic) can provide data on the activity, arrhythmic events and electrophysiology of the individual. These data might improve the diagnostic potential of $\mathrm{HF}$, but we were able to establish a new ITI parameter, ITI ratio, for detecting subclinical increases in BNP, and this provides the rationale for further testing. Second, this study included HF patients with both reduced EF and preserved EF. CRT-D was implanted in the patients with reduced EF, and ICD was more likely to be used in those patients with preserved EF. In both the patients with preserved EF and with reduced EF, however, ITI ratio was correlated with the difference in log BNP. Trends in ITI before HF events and the optimal cut-off point of the ITI ratio may be different between patients with preserved EF and with reduced EF. Finally, it is difficult to know whether baseline truly represents the dry impedance in these patients. In this study, we measured baseline ITI when patient condition was stable and they were without symptomatic HF.

\section{Conclusions}

Use of an implantable diagnostic tool to measure fluid index did not diagnose the worsening of HF (increase in BNP). Decrease in ITI as compared with baseline, however, may be a useful marker of worsening HF.

\section{Acknowledgments}

We thank Yoshimasa Tsushima, MD; Hiroshi Kawamura, MD; Hiroshi Tasaka, MD; Kohei Miyaji, MD; Satoshi Kawata, MD; Kenji Kawamoto, MD; Shigeki Hiramatsu, MD; Akihiro Hayashida, MD; Keisuke Okawa, MD; Chisato Suezawa, MD; Kenji Takagaki, MD; Toshiaki Yamanaka, MD; Yusuke Kawai, MD; Akihito Miyoshi, MD; Hiroki Oe, MD; Hisanori Toh, MD; Toru Miyoshi, MD; Kazufumi Nakamura, MD; Hiromi Matsubara, MD; and Tohru Ohe, MD, for the MOMOTARO investigators. We thank Nobuhisa Watanabe and Yasuharu Tanabe for the echocardiography. We thank Yuki Takenaka for the medical engineering work. We thank Yuko Kobayashi, Kaoru Akazawa, Miyuki Fujiwara, and Masayo Ohmori for assistance with the manuscript.

\section{Disclosures}

Conflict of Interest: This study was supported financially by Medtronic. None of the authors had any additional relationships with industry.

\section{References}

1. Roger VL, Go AS, Lloyd-Jones DM, Benjamin EJ, Berry JD, Borden WB, et al. Heart disease and stroke statistics - 2012 update: A report from the American Heart Association. Circulation 2012; 125: e2-e220, doi:10.1161/CIR.0b013e31823ac046.

2. Cleland JG, Swedberg K, Follath F, Komajda M, Cohen-Solal A,
Aguilar JC, et al. The EuroHeart Failure survey programme - A survey on the quality of care among patients with heart failure in Europe. Part 1: Patient characteristics and diagnosis. Eur Heart J 2003; 24: $442-463$.

3. Chaudhry SI, Mattera JA, Curtis JP, Spertus JA, Herrin J, Lin Z, et al. Telemonitoring in patients with heart failure. N Engl J Med 2010; 363: 2301-2309.

4. Koehler F, Winkler S, Schieber M, Sechtem U, Stangl K, Bohm M, et al. Impact of remote telemedical management on mortality and hospitalizations in ambulatory patients with chronic heart failure: The telemedical interventional monitoring in heart failure study. Circulation 2011; 123: 1873-1880.

5. Yu CM, Wang L, Chau E, Chan RH, Kong SL, Tang MO, et al. Intrathoracic impedance monitoring in patients with heart failure: Correlation with fluid status and feasibility of early warning preceding hospitalization. Circulation 2005; 112: 841-848.

6. Zile MR, Bennett TD, St John Sutton M, Cho YK, Adamson PB, Aaron MF, et al. Transition from chronic compensated to acute decompensated heart failure: Pathophysiological insights obtained from continuous monitoring of intracardiac pressures. Circulation 2008; 118: $1433-1441$.

7. Abraham WT, Adamson PB, Bourge RC, Aaron MF, Costanzo MR, Stevenson LW, et al. Wireless pulmonary artery haemodynamic monitoring in chronic heart failure: A randomised controlled trial. Lancet 2011; 377: 658-666.

8. Ritzema J, Troughton R, Melton I, Crozier I, Doughty R, Krum H, et al. Physician-directed patient self-management of left atrial pressure in advanced chronic heart failure. Circulation 2010; 121: 1086-1095.

9. Taniguchi Y, Emoto N, Miyagawa K, Nakayama K, Kinutani H, Tanaka $\mathrm{H}$, et al. Noninvasive and simple assessment of cardiac output and pulmonary vascular resistance with whole-body impedance cardiography is useful for monitoring patients with pulmonary hypertension. Circ J 2013; 77: 2383-2389.

10. Vollmann D, Nagele H, Schauerte P, Wiegand U, Butter C, Zanotto $\mathrm{G}$, et al. Clinical utility of intrathoracic impedance monitoring to alert patients with an implanted device of deteriorating chronic heart failure. Eur Heart J 2007; 28: 1835-1840.

11. Catanzariti D, Lunati M, Landolina M, Zanotto G, Lonardi G, Iacopino $\mathrm{S}$, et al. Monitoring intrathoracic impedance with an implantable defibrillator reduces hospitalizations in patients with heart failure. Pacing Clin Electrophysiol 2009; 32: 363-370.

12. Small RS, Wickemeyer W, Germany R, Hoppe B, Andrulli J, Brady $\mathrm{PA}$, et al. Changes in intrathoracic impedance are associated with subsequent risk of hospitalizations for acute decompensated heart failure: Clinical utility of implanted device monitoring without a patient alert. J Card Fail 2009; 15: 475-481.

13. Whellan DJ, Ousdigian KT, Al-Khatib SM, Pu W, Sarkar S, Porter $\mathrm{CB}$, et al. Combined heart failure device diagnostics identify patients at higher risk of subsequent heart failure hospitalizations: Results from PARTNERS HF (Program to Access and Review Trending Information and Evaluate Correlation to Symptoms in Patients With Heart Failure) study. J Am Coll Cardiol 2010; 55: 1803-1810.

14. Conraads VM, Tavazzi L, Santini M, Oliva F, Gerritse B, Yu CM, et al. Sensitivity and positive predictive value of implantable intrathoracic impedance monitoring as a predictor of heart failure hospitalizations: The SENSE-HF trial. Eur Heart J 2011; 32: 2266-2273.

15. van Veldhuisen DJ, Braunschweig F, Conraads V, Ford I, Cowie MR, Jondeau G, et al. Intrathoracic impedance monitoring, audible patient alerts, and outcome in patients with heart failure. Circulation 2011; 124: 1719-1726.

16. Abraham WT, Compton S, Haas G, Foreman B, Canby RC, Fishel $\mathrm{R}$, et al. Intrathoracic impedance vs daily weight monitoring for predicting worsening heart failure events: Results of the Fluid Accumulation Status Trial (FAST). Congest Heart Fail 2011; 17: 51 -55.

17. Cowie MR, Sarkar S, Koehler J, Whellan DJ, Crossley GH, Tang $\mathrm{WH}$, et al. Development and validation of an integrated diagnostic algorithm derived from parameters monitored in implantable devices for identifying patients at risk for heart failure hospitalization in an ambulatory setting. Eur Heart $J$ 2013; 34: 2472-2480.

18. Soga Y, Ando K, Arita T, Hyodo M, Goya M, Iwabuchi M, et al. Efficacy of fluid assessment based on intrathoracic impedance monitoring in patients with systolic heart failure. Circ J 2011; 75: 129134.

19. Asada K, Fujiu K, Imai Y, Kojima T, Sugiyama H, Suzuki T, et al. Intrathoracic impedance monitoring in patients with heart failure: Correlation with dehydration and bleeding events. Circ J 2012; 76: $2592-2598$

20. Yancy CW, Jessup M, Bozkurt B, Butler J, Casey DE Jr, Drazner MH, et al. 2013 ACCF/AHA guideline for the management of heart failure: A report of the American College of Cardiology Foundation/ 
American Heart Association Task Force on Practice Guidelines. $J$ Am Coll Cardiol 2013; 62: e147-e239, doi:10.1016/j.jacc.2013.05.019.

21. Knudsen CW, Omland T, Clopton P, Westheim A, Wu AH, Duc P, et al. Impact of atrial fibrillation on the diagnostic performance of B-type natriuretic peptide concentration in dyspneic patients: An analysis from the breathing not properly multinational study. $J \mathrm{Am}$ Coll Cardiol 2005; 46: 838-844.

22. Brignole M, Occhetta E, Bongiorni MG, Proclemer A, Favale S, Iacopino $\mathrm{S}$, et al. Clinical evaluation of defibrillation testing in an unselected population of 2,120 consecutive patients undergoing first implantable cardioverter-defibrillator implant. J Am Coll Cardiol 2012; 60: $981-987$.

23. Wang L, Lahtinen S, Lentz L, Rakow N, Kaszas C, Ruetz L, et al. Feasibility of using an implantable system to measure thoracic congestion in an ambulatory chronic heart failure canine model. Pacing Clin Electrophysiol 2005; 28: 404-411.

24. Vanderheyden M, Houben R, Verstreken S, Stahlberg M, Reiters P, Kessels R, et al. Continuous monitoring of intrathoracic impedance and right ventricular pressures in patients with heart failure. Circ Heart Fail 2010; 3: 370-377.

25. Lüthje L, Vollmann D, Drescher T, Schott P, Zenker D, Hasenfuss $\mathrm{G}$, et al. Intrathoracic impedance monitoring to detect chronic heart failure deterioration: Relationship to changes in NT-proBNP. Eur $J$
Heart Fail 2007; 9: 716-722.

26. Connolly SJ, Kerr CR, Gent M, Roberts RS, Yusuf S, Gillis AM, et al. Effects of physiologic pacing versus ventricular pacing on the risk of stroke and death due to cardiovascular causes: Canadian Trial of Physiologic Pacing Investigators. N Engl J Med 2000; 342: $1385-$ 1391.

27. Raatikainen MJ, Uusimaa P, van Ginneken MM, Janssen JP, Linnaluoto M. Remote monitoring of implantable cardioverter defibrillator patients: A safe, time-saving, and cost-effective means for follow-up. Europace 2008; 10: $1145-1151$

28. Varma N, Epstein AE, Irimpen A, Schweikert R, Love C. Efficacy and safety of automatic remote monitoring for implantable cardioverterdefibrillator follow-up: The Lumos-T Safely Reduces Routine Office Device Follow-up (TRUST) trial. Circulation 2010; 122: 325-332.

29. Watanabe E, Kasai A, Fujii E, Yamashiro K, Brugada P. Reliability of implantable cardioverter defibrillator home monitoring in forecasting the need for regular office visits, and patient perspective. Japanese HOME-ICD study. Circ J 2013; 77: 2704-2711.

30. Saxon LA, Hayes DL, Gilliam FR, Heidenreich PA, Day J, Seth M, et al. Long-term outcome after ICD and CRT implantation and influence of remote device follow-up: The ALTITUDE survival study. Circulation 2010; 122: 2359-2367. 